\title{
Smooth Muscle and Other Cell Sources for Human Blood Vessel Engineering
}

\author{
Sumati Sundaram Laura E. Niklason \\ Departments of Biomedical Engineering and Anesthesia, Yale University, New Haven, Conn., USA
}

\section{Key Words}

Stem cells · Tissue engineering • Blood vessel engineering • Smooth muscle cells $\cdot$ Induced pluripotent stem cells

\begin{abstract}
Despite substantial progress in the field of vascular tissue engineering over the past decades, transition to human models has been rather challenging. The limited replicative life spans of human adult vascular cells, and their slow rate of collagenous matrix production in vitro, have posed important hurdles in the development of mechanically robust and biologically functional engineered grafts. With the more recent advances in the field of stem cells, investigators now have access to a plethora of new cell source alternatives for vascular engineering. In this paper, we review various alternative cell sources made available more recently for blood vessel engineering and also present some recent data on the derivation of smooth muscle cells from human induced pluripotent stem cells.

Copyright $\odot 2011$ S. Karger AG, Basel
\end{abstract}

\section{Introduction}

More than 500,000 bypass procedures are performed each year in the USA alone [Roger et al., 2011]. Both venous and arterial grafts such as the saphenous vein or the internal mammary or radial artery are widely employed.
However, due to age, disease, or prior usage, many patients may not have suitable autologous arteries or veins. Since Weinberg and Bell [1986] first sparked the idea of growing a living blood vessel in vitro by seeding collagen gel tubes, the field of tissue engineering of blood vessels has expanded tremendously. Researchers have expanded on this original idea of seeding arterial cells onto natural or synthetic materials by employing different kinds of bioreactors to make tubular constructs and subjecting them to soluble factors and/or mechanical conditioning

\section{Abbreviations used in this paper}

ASCs adipose-derived stem cells

EBs embryoid bodies

ECs endothelial cells

ESCs embryonic stem cells

hESCs human embryonic stem cells

hiPSCs human induced pluripotent stem cells

iPS induced pluripotent stem

MSCs mesenchymal stem cells

PDs population doublings

PGA polyglycolic acid

SCID severe combined immune deficiency

SMA smooth muscle actin

SMCs smooth muscle cells

TEBVs tissue-engineered blood vessels

TEVGs tissue-engineered vascular grafts

\section{KARGER}

() 2011 S. Karger AG, Basel

Fax +41613061234

E-Mail karger@karger.ch

www.karger.com
Accessible online at: www.karger.com/cto
Dr. Laura E. Niklason

Departments of Biomedical Engineering and Anesthesia, Yale University 10 Amistad Street

New Haven, CT 06510 (USA)

Tel. +1 203737 1422, E-Mail laura.niklason@yale.edu 
to improve the properties of the living blood vessel graft. There are several excellent reviews that discuss these topics in great detail [Gong and Niklason, 2006; Isenberg et al., 2006; L'Heureux et al., 2007a]. This review mainly focuses on the variety of alternative cell sources made available more recently for the engineering of vessel substitutes, evaluating their respective advantages and limitations. Additionally, while we have included some useful information on endothelial cells (ECs), this article mainly focuses on cell sources for smooth muscle cells (SMCs).

\section{General Considerations for Arterial Engineering}

The approaches for generating tissue-engineered blood vessels (TEBVs) in vitro generally require culture times of 8-24 weeks or longer so that cells can generate adequate extracellular matrix to produce mechanical properties requisite for arterial grafts. During extended cell culture in the presence of growth factors, vascular cells are stimulated to replicate extensively. For example, to produce mechanically robust vessel substitutes, SMCs must proliferate for at least 45-60 population doublings (PDs) [L'Heureux et al., 1998; Niklason et al., 1999; Poh et al., 2005]. While fetal and neonatal cells of various species (bovine, porcine, human) can divide extensively in culture, nonneonatal adult human SMCs typically proliferate for 10-30 PDs before undergoing senescence [Burton et al., 2009]. Cellular age also influences the mechanical strength of engineered vessels. It is known that the mechanical strength of the vessel is largely derived from the extracellular matrix components such as collagen and elastin. With its high tensile strength, collagen maintains the structural integrity of a vessel. Elastin acts as a recoil protein and contributes to the compliance of the vessel. In general, older cells deposit less extracellular matrix than younger cells due to downregulation of matrix production and elastogenesis [McMahon et al., 1985; Johnson et al., 1995]. This leads to generation of vessel grafts with poor mechanical properties such as burst pressure and suture retention. Hence, it has been particularly difficult to generate vessel grafts with adequate mechanical properties using older cells - matrix deposition occurs but at a much slower rate than with younger cells. Such observations may underlie observations by L'Heureux and colleagues [Konig et al., 2009], who have been successful in utilizing older human fibroblasts to produce vessel grafts but at a cost of culture times exceeding 6 months.
The limited replicative capacity of adult vascular cells is due in part to the progressive shortening of the telomeres with donor age. Ectopic expression of telomerase in somatic cells has been shown to reverse the telomere shortening and to extend the replicative life span of a variety of cell types, including SMCs and ECs [Yang et al., 2001; Kobune et al., 2003; Poh et al., 2005]. Poh et al. [2005] introduced telomerase into SMCs derived from saphenous vein cells from patients who were undergoing coronary artery bypass grafting. The resulting cells proliferated far beyond their normal life span, and the vessels generated using the telomerase-infected SMCs were mechanically more robust than those generated from control SMCs. However, extracellular matrix accumulation in engineered arteries was inversely proportional to donor age despite life span extension using telomerase. In addition, retroviral gene therapy with telomerase raises some safety concerns since random incorporation of retroviral vectors may activate oncogenes [European Society of Gene Therapy, 2003; Klinger et al., 2006]. Hence, both cellular life span and collagenous extracellular matrix production are important for in vitro vascular tissue engineering.

\section{Cell Sources for Engineering Blood Vessel Grafts: Successful Approaches}

Approaches utilizing differentiated animal ECs, SMCs [Niklason et al., 1999], and fibroblasts [Konig et al., 2009; Syedain et al., 2011] to create vessel substitutes have had varying degrees of success, depending on the species [Niklason et al., 2001] and the age of the cell donors [Solan and Niklason, 2005; Han et al., 2010].

L'Heureux and colleagues utilized autologous fibroblasts from human adults to produce sheets of tissue that were then fused around a stainless steel mandrel to generate mechanically robust vessels with burst strengths greater than 3,000 mg [Konig et al., 2009]. As noted above, this process takes 6-9 months for the creation of the tissue-engineered vascular grafts (TEVGs). More recently, an impressive milestone was achieved in the transition to clinical human application of such TEVGs [L'Heureux et al., 2007b; McAllister et al., 2009]. Studies were performed by Cytograft (Novato, California) in a challenging patient population, specifically those with end-stage renal disease that had already had at least one previous hemodialysis access failure. TEVGs were implanted as arteriovenous shunts in 10 adult patients ranging in age from 29 to 89 years. In a more recent report, the 6-month 
effectiveness of the whole cohort of 10 patients was presented [McAllister et al., 2009]. Overall, graft patency was achieved for 68 patient-months. While the long culture time of over 9 months required to produce these grafts might be a deterrent for clinical applications where patients are in need of a graft more urgently, nevertheless, these results are extremely encouraging and represent a significant step forward in the clinical application of human TEBV grafts.

In a more recent report, Syedain et al. [2011] demonstrated the ability to generate tissue-engineered arteries similar to native arteries by entrapment of human neonatal dermal fibroblasts in a fibrin gel. A bioreactor was developed to impart both cyclic distension and transmural flow to all grafts via a common manifold [Syedain et al., 2008]. After 7-9 weeks of culture, grafts containing circumferentially aligned collagen and other extracellular matrix were created with burst pressures in the range of $1,400-1,600 \mathrm{~mm} \mathrm{Hg}$ and compliance comparable to that of native arteries. Both 2- and 4-mm grafts with suture retention strengths sufficient for implantation in small animal models were created. The relatively short time period required and the notable mechanical properties of the grafts generated using this method are extremely encouraging.

Dahl et al. [2011] demonstrated the successful application of differentiated cells to generate 'off-the-shelf' TEVGs. The researchers created TEVGs with mechanical properties equivalent to those of native vessels by seeding allogeneic SMCs from adult human donor tissues (age 17-49 years) on biodegradable polyglycolic acid (PGA) scaffolds in a bioreactor that delivers a cyclic radial strain for 8-10 weeks. At the end of the culture period, the tubular vascular tissue mainly comprising secreted matrix proteins was decellularized to remove the antigenic cellular material, thereby allowing the use of banked allogeneic cells to produce TEVGs that are nonimmunogenic and can therefore be utilized in an off-the-shelf manner in any recipient. The decellularized large-diameter (6 $\mathrm{mm})$ TEVGs generated demonstrated a high burst pressure (approximately 3,000 $\mathrm{mm} \mathrm{Hg}$ ) equivalent to that of native vessels and retained mechanical properties even after 12 months of storage at $4^{\circ} \mathrm{C}$. The TEVGs were then tested in a baboon arteriovenous model for 1-6 months. The overall patency was $88 \%$. Further successful application in human patients as well as testing of small-diameter human TEVGs using this same concept remains to be seen.

To date, the most successful approaches tested with human cells and in patients still require long culture times and pose particular challenges when donors are elderly. Given the long culture times, and the poor matrix production of older cells, the search continues for a better cell source that could produce more collagenous matrix more quickly and be more readily available.

\section{Adult Cells - Progenitor Cells}

\section{Mesenchymal Stem Cells}

Mesenchymal stem cells (MSCs) are generally isolated from the heterogeneous mononuclear cell fraction of the bone marrow but can also be found in nonmarrow sources. These cells do not have a distinct phenotype marker but are defined by the presence of a set of markers such as CD29, CD44, CD71, CD90, CD106a, CD120a, SH2, $\mathrm{SH} 3$, and SH4 and the absence of markers such as CD14, CD34, CD45, CD31, and HLA-DR. They have the ability to differentiate into a variety of cell lineages [Pittenger et al., 1999; Jiang et al., 2002] such as osteoblasts, adipocytes, chondrocytes, and myoblasts.

Differentiation of MSCs into SMCs has been studied extensively. As early as 1993, Galmiche et al. [1993] documented that stromal cells from human long-term marrow cultures are mesenchymal cells that differentiate along a vascular smooth muscle differentiation pathway. Various factors such as soluble growth factors, cell-cell contact, mechanical stimulation, and extracellular matrix substrate proteins are known to have an effect on the differentiation of MSCs. TGF $\beta 1$ plays a significant role in the extent of differentiation of MSCs to calponin-positive SMCs [Gong et al., 2008]. Apart from growth factors and cellular microenvironments, mechanical conditioning such as application of cyclic strain [Kurpinski et al., 2006] has been shown to enhance extracellular matrix remodeling and synthesis as well as cellular proliferation of differentiated SMCs. The capacity of MSCs to differentiate into ECs remains an unresolved issue, though it is likely that purified MSC populations probably do not have extensive ability to differentiate into endothelium. While a few studies have demonstrated the ability to differentiate MSCs into ECs expressing markers such as Flk-1, Tie-1, Tie-2, and vWF [Oswald et al., 2004; Gang et al., 2006], others have reported the inability to differentiate MSCs into ECs in vitro [Au et al., 2008].

Researchers have also attempted to utilize MSCs for engineering blood vessel grafts. Andreadis and colleagues successfully derived ovine bone marrow smooth muscle progenitor cells using a tissue-specific promoter and further utilized these cells to make vascular grafts by 
embedding the cells in fibrin hydrogels around 4-mm mandrels [Liu et al., 2007]. The grafts were tested as interpositional grafts in jugular veins of lambs. Five weeks postimplanation, the explanted grafts showed a confluent endothelial monolayer and circumferentially aligned SMCs close to the lumen, as well as high levels collagen and fibrillar elastin similar to native veins.

The application of MSCs in human vascular tissue engineering is just emerging. Human bone marrow-derived MSCs can be used to engineer blood vessel grafts [Gong and Niklason, 2008], though to date the matrix expression from these cells has been insufficient to produce mechanics necessary for arterial implantation. The cellular microenvironment most conducive to the differentiation of MSCs into calponin-expressing SMCs involved the growth factors TGF $\beta 1$, PDGF-BB, and bFGF, as well as cyclic mechanical strain and extracellular matrix proteins such as fibronectin. Vessel grafts obtained after 8 weeks of culture stained positive for smooth muscle markers smooth muscle actin (SMA) and calponin, which confirms the SMC differentiation. Vessels contained 22\% collagen by dry weight, which is about half that of native vessels, and had burst pressures of over $200 \mathrm{~mm} \mathrm{Hg}$.

Several groups have also attempted to directly implant MSCs in vivo to aid vascular regeneration. For example, Au et al. [2008] were able to form a network of long-lasting blood vessels by coimplantation of HUVECs and human MSCs in a 3-D fibronectin-type I collagen gel into immunocompromised mice. To permit continuous observation of the networks, the constructs were implanted into mice bearing transparent 'windows' and the EGFP gene was introduced to track the implanted cells. Engineered blood vessels derived from HUVECs and MSCs in severe combined immune deficiency (SCID) mice remained stable for 130 days in vivo. Hashi et al. [2007] demonstrated that MSCs seeded on nanofibrous aligned conduits allow efficient infiltration of vascular cells and matrix remodeling. In vivo implantation of MSC-seeded conduits in rat carotid arteries showed well-formed layers of endothelial and smooth muscle layers. These biodegradable nanofibrous scaffolds were prepared with aligned nanofibers that mimicked native collagen fibrils to guide cell organization in the grafts. The long-term patency of cellular grafts was attributed to the antithrombogenic property of MSCs.

To avoid time-consuming cell cultures for expansion of MSCs, several groups [Hibino et al., 2005] have started testing the utilization of a whole mononuclear fraction of bone marrow with reasonable success. In a significant step forward, Shin'oka et al. [2005] utilized autologous mononuclear bone marrow cell-seeded tissue-engineered vessel grafts in pediatric patients [Hibino et al., 2010] The tubular grafts were patent for at least 32 months and showed no aneurysm formation or calcification. These studies exhibit promising results for TEVGs in low-pressure applications, such as venous or pulmonary arterial replacement, particularly in younger patients.

\section{Adipose-Derived Stem Cells and Other Sources}

Since being originally characterized in 2002 [Zuk et al., 2002], adipose-derived stem cells (ASCs) have gained great attention as an easily accessible source of autologous cells. ASCs are phenotypically similar to bone marrowderived MSCs but lack expression of CD106, among other markers, suggesting that they are a distinct population of cells of mesenchymal origin. Clonal expansions derived from ASCs demonstrate multipotency as well as a self-renewing capacity similar to that of MSCs [Rodriguez et al., 2006]. ASCs have the capacity to differentiate into myogenic, adipogenic, osteogenic, chondrogenic, and neurogenic lineages. Researchers have demonstrated the ability of processed human lipoaspirates to differentiate into functional contractile SMCs [Rodriguez et al., 2006] as well as into ECs [Planat-Benard et al., 2004]. The frequency of ASCs in an aspirate of adipose tissue is approximately $3 \%$, while the frequency of similar cells in bone marrow aspirates is almost 3 orders of magnitude lower.

ASCs are being pursued as an attractive cell source for vascular regeneration. Wang et al. [2010] have successfully engineered small-diameter vessels utilizing human ASCs. Human ASCs obtained from the stromal fraction of lipoaspirates of healthy patients (average age 30 years) were differentiated into functional SMCs using TGF $\beta 1$ and BMP4. These differentiated cells were then seeded on PGA polymer mesh and grown for 8 weeks in a pulsatile bioreactor system. Under dynamic conditions, the vessels demonstrated good biomechanical properties and collagen deposition of about $50 \mu \mathrm{g} / \mathrm{g}$ of wet weight, which is still a fraction of the value for native arteries. Studies by DiMuzio and Tulenko [2007] suggest that the isolation efficiency of ASCs from patients from fat derived via liposuction is not affected by patient age, obesity, renal failure, or vascular disease, except that in diabetic patients smaller numbers of cells were isolated. Based on a cell growth 1 week postharvest, the authors speculate that an average of only $50-100 \mathrm{~g}$ of adipose tissue would be required to seed the luminal surface of a $40 \mathrm{~cm} \times 6 \mathrm{~mm}$ 
bypass graft. Overall, these studies suggest that ASCs could be a practical source of autologous adult stem cells to be employed for vascular regeneration and vessel engineering.

More recently, hair follicles have been shown to contain multipotent stem cells having the ability to regenerate the epidermis as well as mesenchymal and hematopoietic lineages [Lako et al., 2002; Amoh et al., 2010]. Andreadis and colleagues have exploited hair follicles as a novel cell source to derive contractile SMCs from both ovine [Liu et al., 2008] and human sources [Liu et al., 2010]. The same group further utilized ovine hair folliclederived SMCs on decellularized small intestine submucosa to regenerate a mechanically robust vascular media [Peng et al., 2011].

\section{Embryonic Stem Cells}

Embryonic stem cells (ESCs) are cells that are derived from preimplantation embryos at the blastocyst stage [Thomson et al., 1998]. To date, researchers have successfully derived ECs and SMCs from human ESC (hESC) lines. Several different strategies have been explored to derive SMCs from hESCs. Progenitor cells such as CD34+ cells have been isolated either from spontaneously differentiated embryoid bodies (EBs) [Ferreira et al., 2007; Vazão et al., 2011] or from cocultures [Hill et al., 2010] and then further induced with factors such as TGF $\beta 1$, PDGF-BB, retinoic acid, or a combination thereof to aid the differentiation into SMC-like cells. Others have utilized a combination of inductive cell culture medium along with extracellular matrix such as collagen IV [Vo et al., 2010] or Matrigel [Xie et al., 2007] to favor SMC differentiation. ECs have also been derived from hESCs by using PECAM antibodies to select for these cells [Levenberg et al., 2002] or by isolating a CD34+ progenitor population from 10- to 15-day EBs that is then differentiated into mature ECs and SMCs [Ferreira et al., 2007]. Several groups have derived ECs from hESCs using 2-D and 3-D cultures [Levenberg et al., 2003] and demonstrated the ability of these cells to form implantable blood vessels as well as vascularized skeletal tissue [Levenberg et al., 2005]. Studies have demonstrated the functionality of ESC-derived cells in animal models. ESC-derived ECs are able to form tubelike structures on Matrigel and formed microvessels when they were transplanted into SCID mice. Using a scalable 2-D differentiation system, Wang et al. [2007] derived ECs from ESCs which, when transplanted into SCID mice, formed blood conduits that were functional for 150 days. However, the functionality of such ESC-derived cells in engineering human vascular grafts still remains to be tested.

\section{Induced Pluripotent Stem Cells}

The creation of induced pluripotent stem (iPS) cells is one of the most important biomedical discoveries of our time. In 2006, researchers showed for the first time that the developmental state of mature cells could be reprogrammed into that of pluripotent embryonic cells by introducing a cocktail of defined transcription factors [Takahashi and Yamanaka, 2006]. These cells were originally created by retroviral delivery of Oct4, Sox 2 combined with Klf4, c-myc or lin28 and Nanog. To address the potential genomic alterations caused due to permanent integration of transgenes, research has been underway utilizing nonintegrating vectors for delivery of reprogramming factors. Methods studied so far include transient transfection of plasmids, nonintegrating adenovirus [Stadtfeld et al., 2008], and a piggyBAC transposon system [Woltjen et al., 2009] as well as Cre/loxP for removal of transgenes once reprogramming is complete [Sommer et al., 2010]. Efforts have also been made to completely replace the reprogramming factors with a cocktail of defined small molecules that can either induce or enhance reprogramming [Lin et al., 2009]. In an exciting milestone, Rossi and colleagues demonstrated the ability to reprogram cells from human skin using synthetic modified RNA, thus completely eliminating the use of DNA [Warren et al., 2010]. Since the original creation of iPS cells from reprogrammed adult fibroblasts, investigators have more recently been able to create iPS cells from several other kinds of human somatic cells such as keratinocytes [Aasen et al., 2008], blood [Loh et al., 2009], neural cells as well as several others, including vascular aortic SMCs [Lee et al., 2010] and ECs [Medici et al., 2010].

Similar to hESCs, iPS cells have been shown to differentiate into a variety of cell types. To date, ECs and endothelial progenitor cells as well as mesenchymal cells have been successfully derived from human iPS cells (hiPSCs). The proliferative capacity as well as the functionality of vascular cells derived from iPS cells seems to depend on the differentiation protocol as well as the origin of the iPS cells. Using an EB method and sorting for CD31+ cells, Li et al. [2011] derived functional ECs from hiPSCs and hESCs [Li et al., 2011]. Gene expression profiling comparing hiPS-ECs and hESC-ECs showed broad similarities 

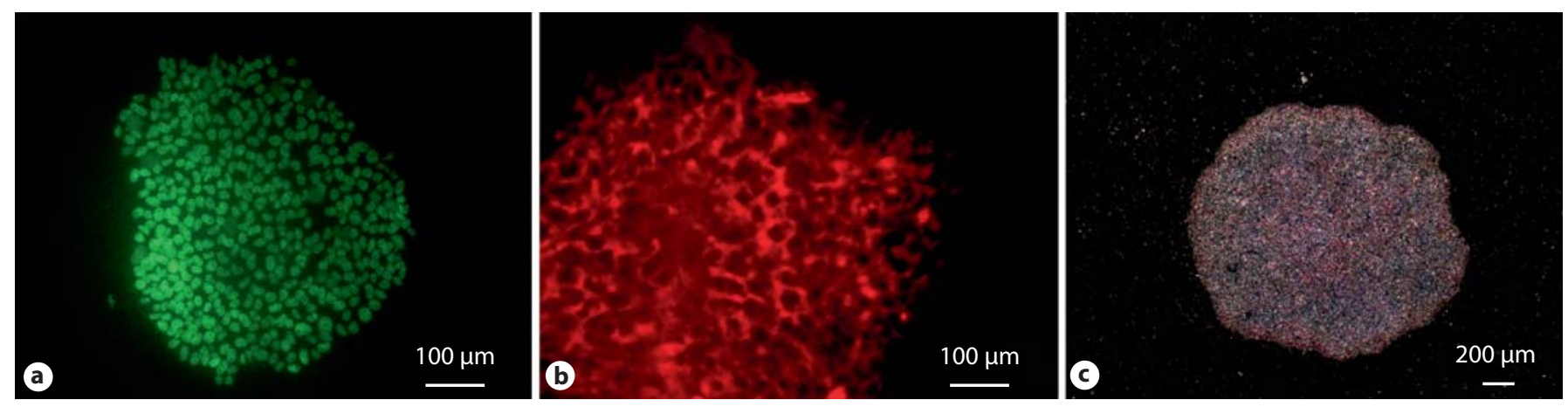

Fig. 1. hiPSCs express pluripotency markers such as Oct4 (a), Tra 1-81 (b), and alkaline phosphatase (c).
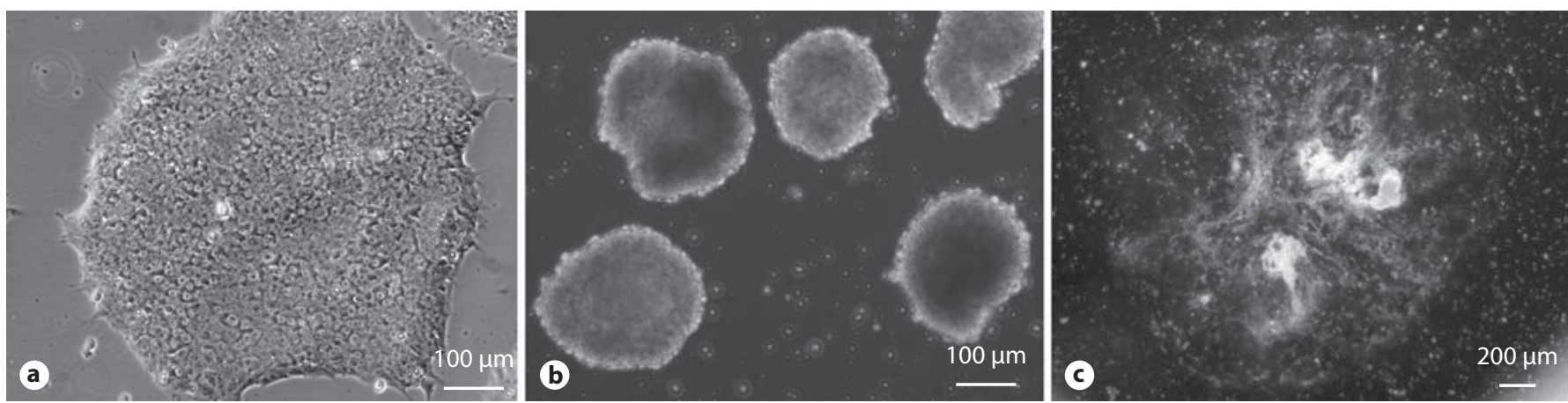

Fig. 2. hiPSC colonies (a) differentiate spontaneously to form EBs (b) and multicellular outgrowths (c).

while also pointing out some differences. hiPS-ECs had a lower G2/M population as compared to hESC-ECs but did not exhibit early senescence or apoptosis. Feng et al. [2010] observed a limited proliferative capacity and early senescence in ECs that were derived from hiPSCs. However, others such as Lian et al. [2010] have been successful in generating mesenchymal cells with high proliferative capacity from hiPSCs [Lian et al., 2010]. These iPS-MSCs generated by sorting for CD24-/CD105+ cells had an excellent proliferative capacity with PDs greater than 120 and were able to differentiate into adipocyte, chondrocyte, and osteocyte lineages. These iPS-MSCs (passage 36) had an almost 10-fold higher activity of telomerase compared to bone-marrow MSCs (passage 6). When tested in a mouse model, iPS-MSCs displayed better functionality in attenuating hind-limb ischemia compared to bone marrow-derived MSCs. While SMCs have been generated from mouse iPS cells [Xie et al., 2009], efforts to derive functional SMCs from hiPSCs are still in early stages. So far, in a proof-of-concept study, Suh and co- workers [Lee et al., 2010] demonstrated the ability to derive iPS cells from human vascular cells and differentiated these iPS cells back into SMCs. The derived SMCs were found to have functional characteristics very similar to those of the original parental SMC cells from which the iPS cells were created.

\section{iPS Cell Differentiation into SMCs}

In our laboratory, we have been culturing hiPSCs (IMR-90, clone 1), and hESCs (H1), to assess differentiation potential into human SMCs. We maintain cells in feeder-free, serum-free conditions on Matrigel-coated plates and routinely passage them every 5-7 days. Cells are monitored regularly by morphology and expression of pluripotency markers (fig. 1).

To initiate differentiation, ES cells and iPS cell colonies are suspended in selected serum, sometimes with retinoic acid. The suspended colonies form EBs (fig. 2b) 
Fig. 3. Immunostaining. Cellular outgrowths derived from hESCs cultured in differentiation conditions for 30 days stain positive for smooth muscle markers such as $\alpha$-SMA (a) and calponin (b).
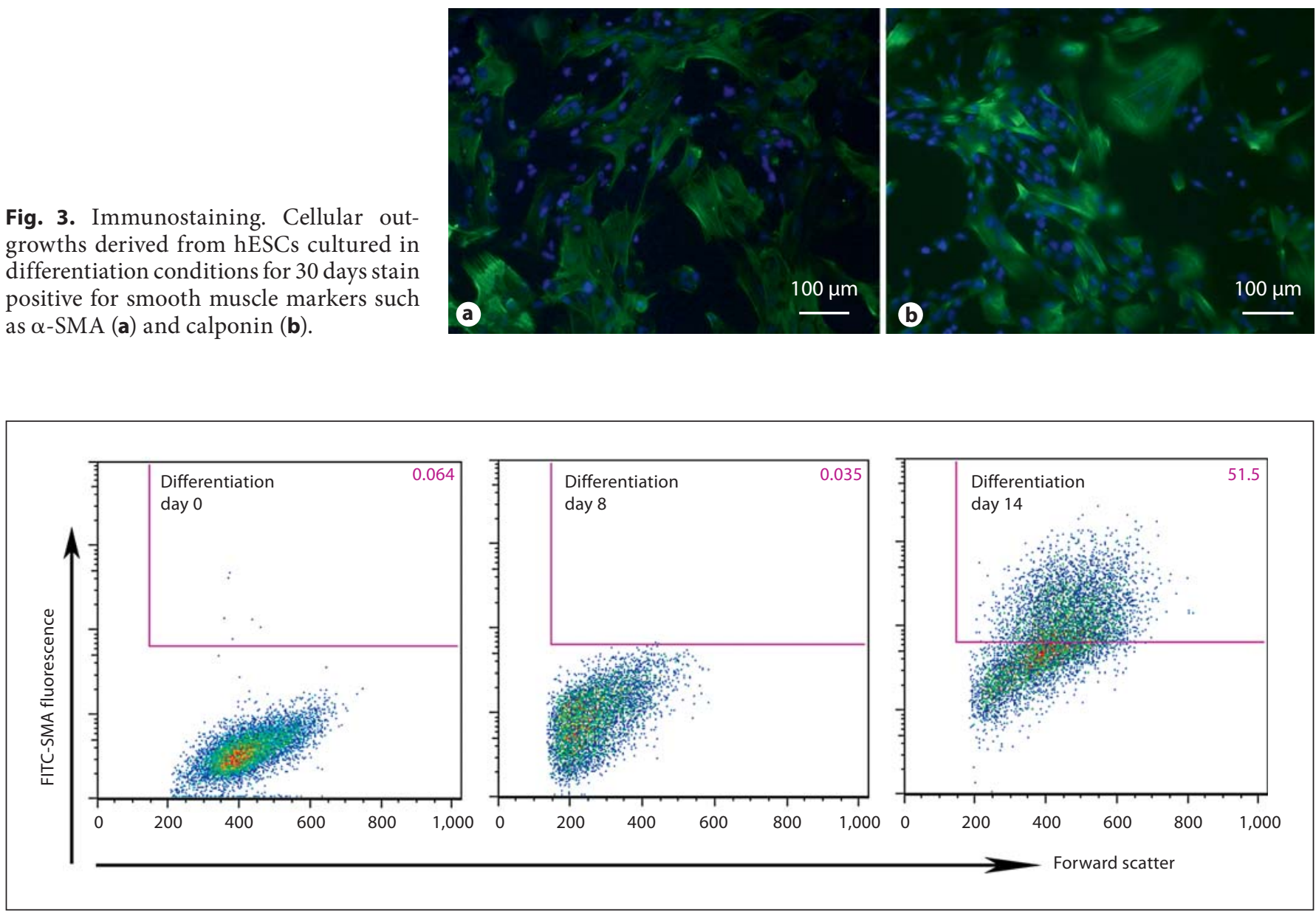

Fig. 4. FACS analysis. Differentiating iPS cells stained for early SMC marker, $\alpha$-SMA, labeled with FITC dye. The X-axis denotes forward scatter units, while the $y$-axis denotes raw fluorescence units.

which when plated on gelatin-coated plates form multicellular outgrowths (fig. 2c). Typically, smooth musclelike cells begin to appear in culture around day 14 . Immunostaining shows SMA- (early) and calponin- (mid) positive cells in the differentiating outgrowths on day 30 (fig. 3). When analyzed by flow cytometry (fig. 4), around $50 \%$ of mixed cell populations expressed intracellular SMA, an early marker of SMCs, on day 14 . Thus, we have demonstrated the ability to differentiate hiPSCs and hESCs into SMA+ and calponin+ cells.

A pilot study was performed to gauge the potential of hiPS-derived cells for vessel engineering. Mixed cell populations containing greater than 50\% SMA-positive cells were seeded onto PGA scaffolds and subjected to cyclic radial stretch as previously described [Niklason et al., 1999; Gong and Niklason, 2008] (fig. 5a). Analysis after 5 weeks of culture (fig. 5b, c) revealed tubular tissue with extensive cellular proliferation and some collagen deposition (16-17\% of dry weight, as compared to $40-50 \%$ by dry weight for native arteries). RT-PCR analysis of vessel lysates confirmed that transcripts of smooth muscle markers such as SM22 $\alpha$ and SMA were present in iPS-derived engineered vessels, while pluripotency markers such as Oct4 were not detected (fig. 6). Further, immunostaining of histology sections indicate the presence of SMA- and calponin-positive cells in the engineered vessels (fig. 7).

Overall, these results are extremely encouraging and provide evidence for the derivation of functional SMCs from hiPSCs. Efforts to improve the efficiency of differentiation as well as further characterization of these derived cells are currently underway. In the future, we will attempt to obtain pure SMCs from the differentiating cell populations. Possible strategies for purification of SMCs include antibiotic selection in the presence of an SMC- 

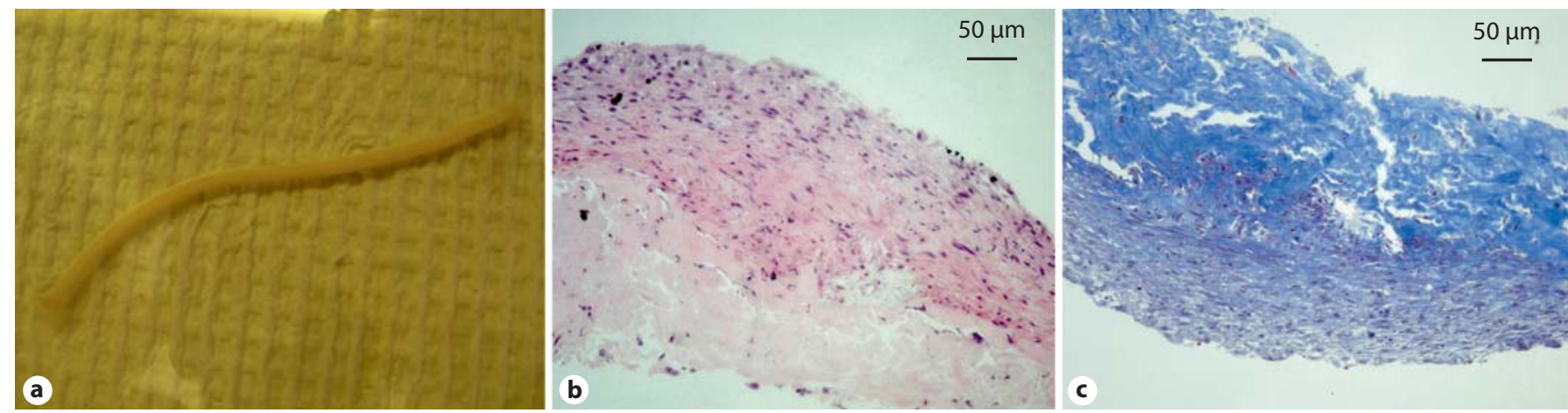

Fig. 5. Pilot study of iPS cell-derived SMCs for generation of TEVGs. a Gross picture of a TEVG generated using iPS cell-derived SMCs. b H\&E staining. c Masson's trichrome staining for collagen.

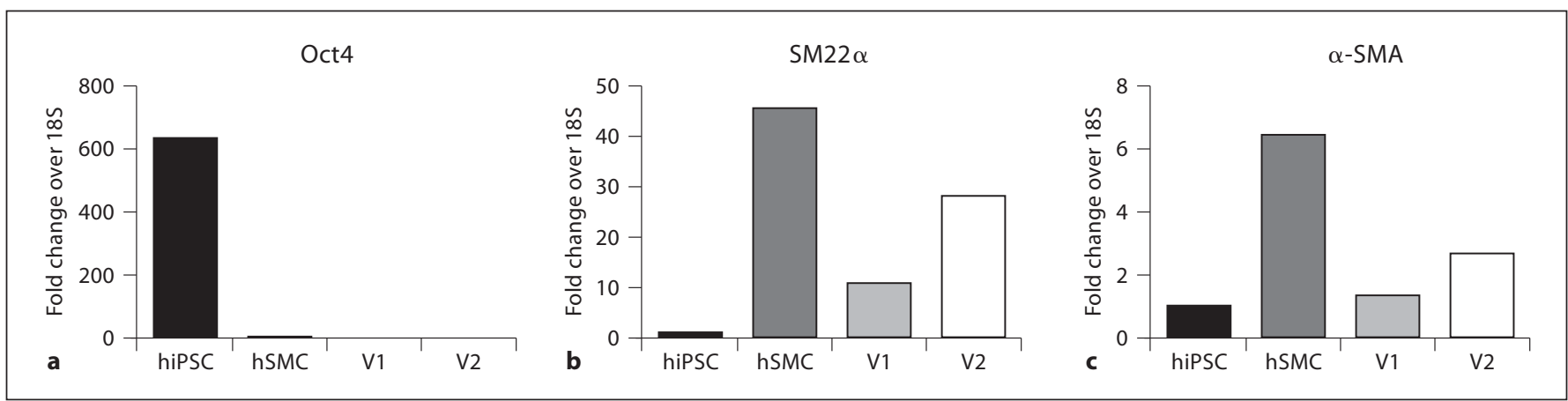

Fig. 6. PCR analysis of TEVG lysates. V1 and V2 denote 2 TEVGs.
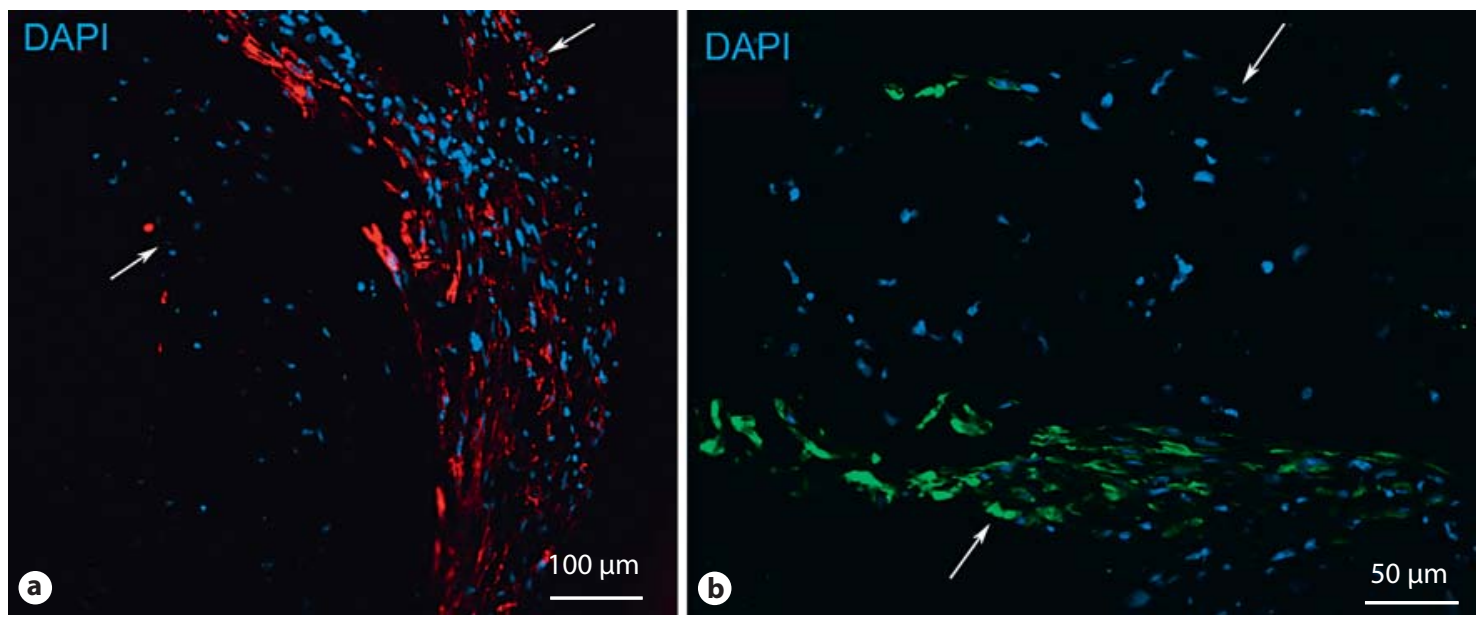

Fig. 7. Immunostaining of TEVGs. a $\alpha$-SMA. b Calponin. Arrows indicate the thickness of the vessel section. 
specific promoter such as $\alpha$-SMA or SM $22 \alpha$, or flow cytometry-based sorting of SMC progenitor cells. Finally, the ability to derive large numbers of SMCs from iPS cells will enable progress towards their application for generation of TEVGs.

\section{Advantages and Limitations of ESCs and iPS Cells}

hESC-derived cells as a therapy for spinal cord injury are being studied in an FDA-approved trial in the USA [Geron Corporation, 2010]. The potential of hiPSCs for use in regenerative medicine is considered to be similar to that of hESCs, and they are free of the ethical dilemmas and potential immune responses associated with the use of hESCs. However, for clinical utilization, iPS cells need to be free of genetic aberrations and capable of differentiating into fully committed cells that maintain their phenotype. It will therefore be essential to assess the state of the reprogrammed and differentiated cells in cellular products. Some recent reports reveal more heterogeneity in gene expression at the single-cell level in hiPSCs than in hESCs [Narsinh et al., 2011] and also warn against mutations in the genome. However, rapid improvements and safer techniques for generation of iPS cells as well as more in-depth analysis of hiPSCs and hESCs hold promise to resolve these issues.

\section{Conclusion}

Development of a tissue-engineered arterial substitute that is mechanically robust and biologically and functionally similar to native vessels is extremely challenging and requires fulfillment of several demanding criteria. From a clinical perspective, one needs to consider the time and cost requirements for the creation of implantable TEVGs for an age- and risk-appropriate patient population. To date, the most successful approaches have utilized differentiated vascular cells and still require long times for generation of TEVGs. Due to their proliferative and differentiative capacity, stem cells open up new alternatives for obtaining autologous cells that may, in the long run, enable production of TEVGs in a more timeefficient manner.

\section{Acknowledgements}

This work was supported by NIH R01 HL083895-05, and by Connecticut Stem Cell grant 08 SCBYSME 025 (both to L.E.N.). L.E.N. has a financial interest in Humacyte, Inc., a regenerative medicine company. Humacyte did not fund these studies, and Humacyte did not affect the design, interpretation, or reporting of any of the experiments herein.

\section{References}

Aasen, T., A. Raya, M.J. Barrero, E. Garreta, A. Consiglio, F. Gonzalez, R. Vassena, J. Bilić, V. Pekarik, G. Tiscornia, M. Edel, S. Boué, J.C. Izpisúa Belmonte (2008) Efficient and rapid generation of induced pluripotent stem cells from human keratinocytes. Nat Biotechnol 26: 1276-1284.

-Amoh, Y., K. Katsuoka, R.M. Hoffman (2010) The advantages of hair follicle pluripotent stem cells over embryonic stem cells and induced pluripotent stem cells for regenerative medicine. J Dermatol Sci 60: 131-137.

-Au, P., J. Tam, D. Fukumura, R.K. Jain (2008) Bone marrow-derived mesenchymal stem cells facilitate engineering of long-lasting functional vasculature. Blood 111: 45514558.

Burton, D.G., P.J. Giles, A.N. Sheerin, S.K. Smith, J.J. Lawton, E.L. Ostler, W. Rhys-Williams, D. Kipling, R.G. Faragher (2009) Microarray analysis of senescent vascular smooth muscle cells: a link to atherosclerosis and vascular calcification. Exp Gerontol 44: 659-665.

Cell Sources for Blood Vessel Engineering
Dahl, S.L., A.P. Kypson, J.H. Lawson, J.L. Blum, J.T. Strader, Y. Li, R.J. Manson, W.E. Tente, L. DiBernardo, M.T. Hensley, R. Carter, T.P. Williams, H.L. Prichard, M.S. Dey, K.G. Begelman, L.E. Niklason (2011) Readily available tissue-engineered vascular grafts. Sci Transl Med 3: 68ra69.

DiMuzio, P., T. Tulenko (2007) Tissue engineering applications to vascular bypass graft development: the use of adipose-derived stem cells. J Vasc Surg 45(suppl A): A99-A103.

European Society of Gene Theapy (2003) French gene therapy group reports on the adverse event in a clinical trial of gene therapy for $\mathrm{X}$ linked severe combined immune deficiency (X-SCID): position statement from the European Society of Gene Therapy. J Gene Med 5: 82-84.

Feng, Q., S.J. Lu, I. Klimanskaya, I. Gomes, D. Kim, Y. Chung, G.R. Honig, K.S. Kim, R. Lanza (2010) Hemangioblastic derivatives from human induced pluripotent stem cells exhibit limited expansion and early senescence. Stem Cells 28: 704-712.
Ferreira, L.S., S. Gerecht, H.F. Shieh, N. Watson, M.A. Rupnick, S.M. Dallabrida, G. VunjakNovakovic, R. Langer (2007) Vascular progenitor cells isolated from human embryonic stem cells give rise to endothelial and smooth muscle like cells and form vascular networks in vivo. Circ Res 101: 286-294.

Galmiche, M.C., V.E. Koteliansky, J. Briere, P. Herve, P. Charbord (1993) Stromal cells from human long-term marrow cultures are mesenchymal cells that differentiate following a vascular smooth muscle differentiation pathway. Blood 82: 66-76.

Gang, E.J., J.A. Jeong, S. Han, Q. Yan, C.J. Jeon, H. Kim (2006) In vitro endothelial potential of human UC blood-derived mesenchymal stem cells. Cytotherapy 8: 215-227.

Geron Corporation (2010) http://clinicaltrials. gov/ct2/show/NCT01217008?term=Geron\& rank=9. 
Gong, Z., G. Calkins, E.C. Cheng, D. Krause, L.E. Niklason (2008) Influence of Culture Medium on Smooth Muscle Cell Differentiation from Human Bone Marrow-Derived Mesenchymal Stem Cells. Tissue Eng Part A 15: 319-330.

-Gong, Z., L.E. Niklason (2006) Blood vessels engineered from human cells. Trends Cardiovasc Med 16: 153-156.

Gong, Z., L.E. Niklason (2008) Small-diameter human vessel wall engineered from bone marrow-derived mesenchymal stem cells (hMSCs). FASEB J 22: 1635-1648.

-Han, J., J.Y. Liu, D.D. Swartz, S.T. Andreadis (2010) Molecular and functional effects of organismal ageing on smooth muscle cells derived from bone marrow mesenchymal stem cells. Cardiovasc Res 87: 147-155.

Hashi, C.K., Y. Zhu, G.Y. Yang, W.L. Young, B.S. Hsiao, K. Wang, B. Chu, S. Li (2007) Antithrombogenic property of bone marrow mesenchymal stem cells in nanofibrous vascular grafts. Proc Natl Acad Sci USA 104: 11915-11920.

-Hibino, N., E. McGillicuddy, G. Matsumura, Y. Ichihara, Y. Naito, C. Breuer, T. Shinoka (2010) Late-term results of tissue-engineered vascular grafts in humans. J Thorac Cardiovasc Surg 139: 431-436, 436.e1-e2.

Hibino, N., T. Shin'oka, G. Matsumura, Y. Ikada, H. Kurosawa (2005) The tissue-engineered vascular graft using bone marrow without culture. J Thorac Cardiovasc Surg 129: 1064 1070.

-Hill, K.L., P. Obrtlikova, D.F. Alvarez, J.A. King, S.A. Keirstead, J.R. Allred, D.S. Kaufman (2010) Human embryonic stem cell-derived vascular progenitor cells capable of endothelial and smooth muscle cell function. Exp Hematol 38: 246-257.e241.

-Isenberg, B.C., C. Williams, R.T. Tranquillo (2006) Small-diameter artificial arteries engineered in vitro. Circ Res 98: 25-35.

-Jiang, Y., B.N. Jahagirdar, R.L. Reinhardt, R.E. Schwartz, C.D. Keene, X.R. Ortiz-Gonzalez, M. Reyes, T. Lenvik, T. Lund, M. Blackstad, J. Du, S. Aldrich, A. Lisberg, W.C. Low, D.A. Largaespada, C.M. Verfaillie (2002) Pluripotency of mesenchymal stem cells derived from adult marrow. Nature 418: 41-49.

-Johnson, D.J., P. Robson, Y. Hew, F.W. Keeley (1995) Decreased elastin synthesis in normal development and in long-term aortic organ and cell cultures is related to rapid and selective destabilization of mRNA for elastin. Circ Res 77: 1107-1113.

Klinger, R.Y., J.L. Blum, B. Hearn, B. Lebow, L.E. Niklason (2006) Relevance and safety of telomerase for human tissue engineering. Proc Natl Acad Sci USA 103: 2500-2505.
Kobune, M., Y. Kawano, Y. Ito, H. Chiba, K. Nakamura, H. Tsuda, K. Sasaki, H. Dehari, H. Uchida, O. Honmou, S. Takahashi, A. Bizen, R. Takimoto, T. Matsunaga, J. Kato, K. Kato, K. Houkin, Y. Niitsu, H. Hamada (2003) Telomerized human multipotent mesenchymal cells can differentiate into hematopoietic and cobblestone area-supporting cells. Exp Hematol 31: 715-722.

Konig, G., T.N. McAllister, N. Dusserre, S.A. Garrido, C. Iyican, A. Marini, A. Fiorillo, H. Avila, W. Wystrychowski, K. Zagalski, M. Maruszewski, A.L. Jones, L. Cierpka, L.M. de la Fuente, N. L'Heureux (2009) Mechanical properties of completely autologous human tissue engineered blood vessels compared to human saphenous vein and mammary artery. Biomaterials 30: 1542-1550.

-Kurpinski, K., J. Chu, C. Hashi, S. Li (2006) Anisotropic mechanosensing by mesenchymal stem cells. Proc Natl Acad Sci USA 103: 16095-16100.

Lako, M., L. Armstrong, P.M. Cairns, S. Harris, N. Hole, C.A. Jahoda (2002) Hair follicle dermal cells repopulate the mouse haematopoietic system. J Cell Sci 115: 3967-3974.

Lee, T.H., S.H. Song, K.L. Kim, J.Y. Yi, G.H. Shin, J.Y. Kim, J. Kim, Y.M. Han, S.H. Lee, S.H. Shim, W. Suh (2010) Functional recapitulation of smooth muscle cells via induced pluripotent stem cells from human aortic smooth muscle cells. Circ Res 106: 120-128.

Levenberg, S., J.S. Golub, M. Amit, J. ItskovitzEldor, R. Langer (2002) Endothelial cells derived from human embryonic stem cells. Proc Natl Acad Sci USA 99: 4391-4396.

Levenberg, S., N.F. Huang, E. Lavik, A.B. Rogers, J. Itskovitz-Eldor, R. Langer (2003) Differentiation of human embryonic stem cells on three-dimensional polymer scaffolds. Proc Natl Acad Sci USA 100: 12741-12746.

Levenberg, S., J. Rouwkema, M. Macdonald, E.S. Garfein, D.S. Kohane, D.C. Darland, R. Marini, C.A. van Blitterswijk, R.C. Mulligan, P.A. D’Amore, R. Langer (2005) Engineering vascularized skeletal muscle tissue. Nat Biotechnol 23: 879-884.

L'Heureux, N., N. Dusserre, A. Marini, S. Garrido, L. de la Fuente, T. McAllister (2007a) Technology insight: the evolution of tissueengineered vascular grafts - from research to clinical practice. Nat Clin Pract Cardiovasc Med 4: 389-395.

L'Heureux, N., T.N. McAllister, L.M. de la Fuente (2007b) Tissue-engineered blood vessel for adult arterial revascularization. $\mathrm{N}$ Engl J Med 357: 1451-1453.

L'Heureux, N., S. Paquet, R. Labbe, L. Germain, F.A. Auger (1998) A completely biological tissue-engineered human blood vessel. FASEB J 12: 47-56.

Li, Z., S. Hu, Z. Ghosh, Z. Han, J.C. Wu (2011) Functional characterization and expression profiling of human induced pluripotent stem cell- and embryonic stem cell-derived endothelial cells. Stem Cells Dev, E-pub ahead of print.
Lian, Q., Y. Zhang, J. Zhang, H.K. Zhang, X. Wu, F.F. Lam, S. Kang, J.C. Xia, W.H. Lai, K.W. $\mathrm{Au}$, Y.Y. Chow, C.W. Siu, C.N. Lee, H.F. Tse (2010) Functional mesenchymal stem cells derived from human induced pluripotent stem cells attenuate limb ischemia in mice. Circulation 121: 1113-1123.

Lin, T., R. Ambasudhan, X. Yuan, W. Li, S. Hilcove, R. Abujarour, X. Lin, H.S. Hahm, E. Hao, A. Hayek, S. Ding (2009) A chemical platform for improved induction of human iPSCs. Nat Methods 6: 805-808.

Liu, J.Y., H.F. Peng, S.T. Andreadis (2008) Contractile smooth muscle cells derived from hair-follicle stem cells. Cardiovasc Res 79: 24-33.

Liu, J.Y., H.F. Peng, S. Gopinath, J. Tian, S.T. Andreadis (2010) Derivation of functional smooth muscle cells from multipotent human hair follicle mesenchymal stem cells. Tissue Eng Part A 16: 2553-2564.

Liu, J.Y., D.D. Swartz, H.F. Peng, S.F. Gugino, J.A. Russell, S.T. Andreadis (2007) Functional tissue-engineered blood vessels from bone marrow progenitor cells. Cardiovasc Res 75: 618-628.

Loh, Y.H., S. Agarwal, I.H. Park, A. Urbach, H. Huo, G.C. Heffner, K. Kim, J.D. Miller, K. Ng, G.Q. Daley (2009) Generation of induced pluripotent stem cells from human blood. Blood 113: 5476-5479.

McAllister, T.N., M. Maruszewski, S.A. Garrido, W. Wystrychowski, N. Dusserre, A. Marini, K. Zagalski, A. Fiorillo, H. Avila, X. Manglano, J. Antonelli, A. Kocher, M. Zembala, L. Cierpka, L.M. de la Fuente, N. L'Heureux (2009) Effectiveness of haemodialysis access with an autologous tissue-engineered vascular graft: a multicentre cohort study. Lancet 373: $1440-1446$

McMahon, M.P., B. Faris, B.L. Wolfe, K.E. Brown, C.A. Pratt, P. Toselli, C. Franzblau (1985) Aging effects on the elastin composition in the extracellular matrix of cultured rat aortic smooth muscle cells. In Vitro cell Dev Biol 21: 674-680.

Medici, D., E.M. Shore, V.Y. Lounev, F.S. Kaplan, R. Kalluri, B.R. Olsen (2010) Conversion of vascular endothelial cells into multipotent stem-like cells. Nat Med 16: 1400-1406.

Narsinh, K.H., N. Sun, V. Sanchez-Freire, A.S. Lee, P. Almeida, S. Hu, T. Jan, K.D. Wilson, D. Leong, J. Rosenberg, M. Yao, R.C. Robbins, J.C. Wu (2011) Single cell transcriptional profiling reveals heterogeneity of human induced pluripotent stem cells. J Clin Invest 121: $1217-1221$.

Niklason, L.E., W. Abbott, J. Gao, B. Klagges, K.K. Hirschi, K. Ulubayram, N. Conroy, R. Jones, A. Vasanawala, S. Sanzgiri, R. Langer (2001) Morphologic and mechanical characteristics of engineered bovine arteries. J Vasc Surg 33: 628-638.

Niklason, L.E., J. Gao, W.M. Abbott, K.K. Hirschi, S. Houser, R. Marini, R. Langer (1999) Functional arteries grown in vitro. Science 284: 489-493. 
Oswald, J., S. Boxberger, B. Jorgensen, S. Feldmann, G. Ehninger, M. Bornhauser, C. Werner (2004) Mesenchymal stem cells can be differentiated into endothelial cells in vitro. Stem Cells 22: 377-384.

Peng, H.F., J.Y. Liu, S.T. Andreadis, D.D. Swartz (2011) Hair follicle-derived smooth muscle cells and small intestinal submucosa for engineering mechanically robust and vasoreactive vascular media. Tissue Eng Part A 17: 981-990.

Pittenger, M.F., A.M. Mackay, S.C. Beck, R.K. Jaiswal, R. Douglas, J.D. Mosca, M.A. Moorman, D.W. Simonetti, S. Craig, D.R. Marshak (1999) Multilineage potential of adult human mesenchymal stem cells. Science 284: 143-147.

Planat-Benard, V., J.S. Silvestre, B. Cousin, M. Andre, M. Nibbelink, R. Tamarat, M. Clergue, C. Manneville, C. Saillan-Barreau, M. Duriez, A. Tedgui, B. Levy, L. Penicaud, L. Casteilla (2004) Plasticity of human adipose lineage cells toward endothelial cells: physiological and therapeutic perspectives. Circulation 109: 656-663.

Poh, M., M. Boyer, A. Solan, S.L. Dahl, D. Pedrotty, S.S. Banik, J.A. McKee, R.Y. Klinger, C.M. Counter, L.E. Niklason (2005) Blood vessels engineered from human cells. Lancet 365: 2122-2124.

Rodriguez, L.V., Z. Alfonso, R. Zhang, J. Leung, B. Wu, L.J. Ignarro (2006) Clonogenic multipotent stem cells in human adipose tissue differentiate into functional smooth muscle cells. Proc Natl Acad Sci USA 103: 1216712172.

Roger, V.L., A.S. Go, D.M. Lloyd-Jones, R.J. Adams, J.D. Berry, T.M. Brown, M.R. Carnethon, S. Dai, G. de Simone, E.S. Ford, C.S. Fox, H.J. Fullerton, C. Gillespie, K.J. Greenlund, S.M. Hailpern, J.A. Heit, P.M. Ho, V.J. Howard, B.M. Kissela, S.J. Kittner, D.T. Lackland, J.H. Lichtman, L.D. Lisabeth, D.M. Makuc, G.M. Marcus, A. Marelli, D.B. Matchar, M.M. McDermott, J.B. Meigs, C.S. Moy, D. Mozaffarian, M.E. Mussolino, G. Nichol, N.P. Paynter, W.D. Rosamond, P.D. Sorlie, R.S. Stafford, T.N. Turan, M.B. Turner, N.D. Wong, J. Wylie-Rosett (2011) Heart disease and stroke statistics - 2011 update: a report from the American Heart Association. Circulation 123: e18-e209.
Shin'oka, T., G. Matsumura, N. Hibino, Y. Naito, M. Watanabe, T. Konuma, T. Sakamoto, M. Nagatsu, H. Kurosawa (2005) Midterm clinical result of tissue-engineered vascular autografts seeded with autologous bone marrow cells. J Thorac Cardiovasc Surg 129: 1330-1338.

Solan, A., L. Niklason (2005) Age effects on vascular smooth muscle: an engineered tissue approach. Cell Transplant 14: 481-488.

Sommer, C.A., A.G. Sommer, T.A. Longmire, C. Christodoulou, D.D. Thomas, M. Gostissa, F.W. Alt, G.J. Murphy, D.N. Kotton, G. Mostoslavsky (2010) Excision of reprogramming transgenes improves the differentiation potential of iPS cells generated with a single excisable vector. Stem Cells 28: 64-74.

Stadtfeld, M., M. Nagaya, J. Utikal, G. Weir, K. Hochedlinger (2008) Induced pluripotent stem cells generated without viral integration. Science 322: 945-949.

Syedain, Z.H., L.A. Meier, J.W. Bjork, A. Lee, R.T. Tranquillo (2011) Implantable arterial grafts from human fibroblasts and fibrin using a multi-graft pulsed flow-stretch bioreactor with noninvasive strength monitoring. Biomaterials 32: 714-722.

Syedain, Z.H., J.S. Weinberg, R.T. Tranquillo (2008) Cyclic distension of fibrin-based tissue constructs: evidence of adaptation during growth of engineered connective tissue. Proc Natl Acad Sci USA 105: 6537-6542.

Takahashi, K., S. Yamanaka (2006) Induction of pluripotent stem cells from mouse embryonic and adult fibroblast cultures by defined factors. Cell 126: 663-676.

Thomson, J.A., J. Itskovitz-Eldor, S.S. Shapiro, M.A. Waknitz, J.J. Swiergiel, V.S. Marshall, J.M. Jones (1998) Embryonic stem cell lines derived from human blastocysts. Science 282: 1145-1147.

Vazão, H., R.P. Neves, M. Grãos, L. Ferreira (2011) Towards the maturation and characterization of smooth muscle cells derived from human embryonic stem cells. PLoS One 6: e17771.

Vo, E., D. Hanjaya-Putra, Y. Zha, S. Kusuma, S. Gerecht (2010) Smooth-muscle-like cells derived from human embryonic stem cells support and augment cord-like structures in vitro. Stem Cell Rev 6: 237-247.
Wang, C., L. Cen, S. Yin, Q. Liu, W. Liu, Y. Cao, L. Cui (2010) A small diameter elastic blood vessel wall prepared under pulsatile conditions from polyglycolic acid mesh and smooth muscle cells differentiated from adipose-derived stem cells. Biomaterials 31 : 621-630.

Wang, Z.Z., P. Au, T. Chen, Y. Shao, L.M. Daheron, H. Bai, M. Arzigian, D. Fukumura, R.K. Jain, D.T. Scadden (2007) Endothelial cells derived from human embryonic stem cells form durable blood vessels in vivo. Nat Biotechnol 25: 317-318.

Warren, L., P.D. Manos, T. Ahfeldt, Y.H. Loh, H. Li, F. Lau, W. Ebina, P.K. Mandal, Z.D. Smith, A. Meissner, G.Q. Daley, A.S. Brack, J.J. Collins, C. Cowan, T.M. Schlaeger, D.J. Rossi (2010) Highly efficient reprogramming to pluripotency and directed differentiation of human cells with synthetic modified mRNA. Cell Stem Cell 7: 618-630.

Weinberg, C.B., E. Bell (1986) A blood vessel model constructed from collagen and cultured vascular cells. Science 231: 397-400.

Woltjen, K., I.P. Michael, P. Mohseni, R. Desai, M. Mileikovsky, R. Hämäläinen, R. Cowling, W. Wang, P. Liu, M. Gertsenstein, K. Kaji, H.K. Sung, A. Nagy (2009) piggyBac transposition reprograms fibroblasts to induced pluripotent stem cells. Nature 458: 766-770.

Xie, C.Q., H. Huang, S. Wei, L.S. Song, J. Zhang, R.P. Ritchie, L. Chen, M. Zhang, Y.E. Chen (2009) A comparison of murine smooth muscle cells generated from embryonic versus induced pluripotent stem cells. Stem Cells Dev 18: 741-748.

Xie, C.Q., J. Zhang, L. Villacorta, T. Cui, H. Huang, Y.E. Chen (2007) A highly efficient method to differentiate smooth muscle cells from human embryonic stem cells. Arterioscler Thromb Vasc Biol 27: e311-312.

Yang, J., U. Nagavarapu, K. Relloma, M.D. Sjaastad, W.C. Moss, A. Passaniti, G.S. Herron (2001) Telomerized human microvasculature is functional in vivo. Nat Biotechnol 19: 219-224

Zuk, P.A., M. Zhu, P. Ashjian, D.A. De Ugarte, J.I. Huang, H. Mizuno, Z.C. Alfonso, J.K. Fraser, P. Benhaim, M.H. Hedrick (2002) Human adipose tissue is a source of multipotent stem cells. Mol Biol Cell 13: 4279-4295. 